\title{
Effects of Remote Stimulation on the Modulated Activity of Cat Retinal Ganglion Cells
}

\author{
Christopher L. Passaglia, ${ }^{1}$ Daniel K. Freeman, ${ }^{1}$ and John B. Troy ${ }^{2}$ \\ ${ }^{1}$ Department of Biomedical Engineering, Boston University, Boston, Massachusetts 02215, and 2Department of Biomedical Engineering, Northwestern \\ University, Evanston, Illinois 60208
}

The output of retinal ganglion cells depends on local and global aspects of the visual scene. The local receptive field is well studied and classically consists of a linear excitatory center and a linear antagonistic surround. The global receptive field contains pools of nonlinear subunits that are distributed widely across the retina. The subunit pools mediate in uncertain ways various nonlinear behaviors of ganglion cells, like temporal-frequency doubling, saccadic suppression, and contrast adaptation. To clarify mechanisms of subunit function, we systematically examined the effect of remote grating patterns on the spike activity of cat X-and Y-type ganglion cells in vivo. We present evidence for two distinct subunit types based on spatiotemporal relationships between response nonlinearities elicited by remote drifting and contrast-reversing gratings. One subunit type is excitatory and activated by gratings of $\sim 0.1$ cycles per degree, while the other is inhibitory and activated by gratings of $\sim 1$ cycle per degree. The two subunit pools contribute to a global gain control mechanism that differentially modulates ganglion cell response dynamics, particularly for ON-center cells, where excitatory and inhibitory subunit stimulation respectively makes responses to antipreferred and preferred contrast steps more transient. We show that the excitatory subunits also have a profound influence on spatial tuning, turning cells from lowpass into bandpass filters. Based on difference-of-Gaussians model fits to tuning curves, we attribute the increased bandpass selectivity to changes in center-surround strength and relative phase and not center-surround size. A conceptual model of the extraclassical receptive field that could explain many observed phenomena is discussed.

Key words: X- and Y-cells; receptive field; nonlinear subunits; contrast gain control; shift effect; maintained discharge

\section{Introduction}

Sensory neurons continually adjust their response characteristics according to prevailing stimulus conditions. In the visual system the mechanisms of response adjustment are diverse and widespread, and they act in space and time on multiple image properties, such as luminance and contrast. Of primary interest here are contrast-dependent processes operating outside the classical receptive field (CRF) of retinal ganglion cells (RGC). Their existence in mammalian retina is long established (Mcllwain, 1964; Levick et al., 1964), and they are thought to underlie certain psychophysical effects of peripheral contrast on foveal target detection (Breitmeyer et al., 1980; He and Loop, 1990). Several processes have been identified based on the assorted physiological phenomena produced by remote stimuli. Together they form what is known as the extraclassical receptive field (ECRF) of RGCs. The ECRF is passed onto lateral geniculate and visual cortical cells where it is further shaped by feedforward, lateral,

Received Aug. 28, 2008; revised Jan. 15, 2009; accepted Jan. 23, 2009.

This work was supported by National Institutes of Health-National Eye Institute Grants F32-EY06908, T32EY07128, and R01-EY06669. We thank Drs. Jennifer Kang-Derwent, Lissa Silver, and Christina Enroth-Cugell for technical assistance.

Correspondence should be addressed to Dr. Christopher L. Passaglia, Department of Biomedical Engineering, Boston University, 24 Cummington Street, Boston, MA 02215. E-mail: psagls@bu.edu.

D01:10.1523/JNEUROSCI.4110-08.2009

Copyright $\odot 2009$ Society for Neuroscience $\quad$ 0270-6474/09/292467-10\$15.00/0 and feedback pathways (Fitzpatrick, 2000; Angelucci and Bressloff, 2006).

One ECRF process is contrast gain control. It modulates RGC responsivity widely across the retina according to the spatiotemporal distribution of contrast in a scene (Shapley and Victor, 1978; Smirnakis et al., 1997; Baccus and Meister, 2002). The breadth of influence distinguishes it from local contrast-adaptive processes, within both the CRF and RGCs themselves, that control response gain and dynamics (Kim and Rieke, 2003; Zaghloul et al., 2005; Beaudoin et al., 2007). It appears to compute contrast by summing signals from pools of nonlinear subunits smaller in size than the CRF center of most RGCs (Shapley and Victor, 1978). The subunits likely correspond to bipolar cell synapses that half-wave rectify their input (Demb et al., 1999, 2001). Those nearby are strong enough to cause measurable contrast adaptation in local RGCs (Brown and Masland, 2001), whereas those afar are weak and large stimulus patterns are required to see their collective effect (Shapley and Victor, 1978).

Other nonlinear phenomena elicited by ECRF stimulation suggest that multiple subunit types are present. One type is presumably responsible for the spike bursts fired by RGCs when a background pattern suddenly shifts (Krüger and Fischer, 1973; Noda and Adey, 1974; Barlow et al., 1977). Shift subunits are also smaller than most RGC centers and their output is synchronous, which may improve feature estimation during fixational eye movements (Greschner et al., 2002). Two other types act to de- 
crease or increase RGC spike rate when a background pattern steadily moves. Mean-decreasing subunits are similarly small and like slow motion, while meanincreasing subunits are larger and prefer fast motion (Passaglia et al., 2001). Additional types may exist that transiently pause RGC spiking after background shifts (Cleland and Levick, 1974; Rapaport and Stone, 1988).

It is unclear whether the various subunits correspond to distinct retinal elements, as some or all of the observed ECRF phenomena might reflect the same underlying circuit interacting nonlinearly with stimuli that differ across studies. In this study we examine ECRF mechanisms within a common population of RGCs and show that local and global contrast gain controls combine in a multifaceted manner that depends on a cell's preferred contrast and the subunit type activated. A functional consequence is that RGCs exhibit more transient responses and greater spatial tuning at high background contrast.

\section{Materials and Methods}

Methods of animal preparation, stimulus display, electrophysiological recording, and data analysis are described by Passaglia et al. (2001). In short, the spike discharges of individual RGCs were recorded extracellularly from the optic tract of anesthetized and paralyzed cats. Heart rate, blood pressure, body temperature, and expired $\mathrm{CO}_{2}$ were monitored and anesthetic and paralytic infusion rates were adjusted to keep the animal in a normal physiological state. Visual stimuli were displayed on a CRT monitor running at $150 \mathrm{~Hz}$ that the animal viewed in a dark room at a distance of $60 \mathrm{~cm}$. At this distance the monitor screen spanned a 30 degree (deg) by 20 deg region of space. The retinal illuminance of the monitor was fixed at 500 cat trolands by dilating the pupils with atropine drops and fitting the eyes with contact lenses having $4 \mathrm{~mm}$ artificial pupils. Displayed images were focused onto the retina via lenses placed in the front of the eyes.

Three kinds of visual patterns were presented to the animal. The first consisted of a large steady uniform gray disk surrounded by a drifting or contrast-reversing sinusoidal grating (Fig. 1a). The disk was generally $10 \mathrm{deg}$ in diameter and was enlarged as needed to prevent the grating from stimulating the CRF of recorded cells and producing a modulated response. The spatial or temporal frequency of the remote grating was varied randomly each trial between $0.1-4$ cycles per degree (cpd) and $0.25-16 \mathrm{~Hz}$, respectively, and the response recorded. The second pattern was identical to the first except that a small spot stepped up and down in luminance (Michelson contrast: $0.02-0.8$ ) at $1 \mathrm{~Hz}$ in the middle of the disk (see Fig. $3 a$ ). The spot was centered on the CRF of recorded cells by positioning the monitor such that responses to horizontally and vertically reversing bipartite fields were minimal. Spot size was matched to the CRF center by estimating center radius from fits of a difference-of-Gaussians model (Rodieck, 1965) to the cells' spatial frequency tuning curve for full-field drifting gratings. Spot responses were
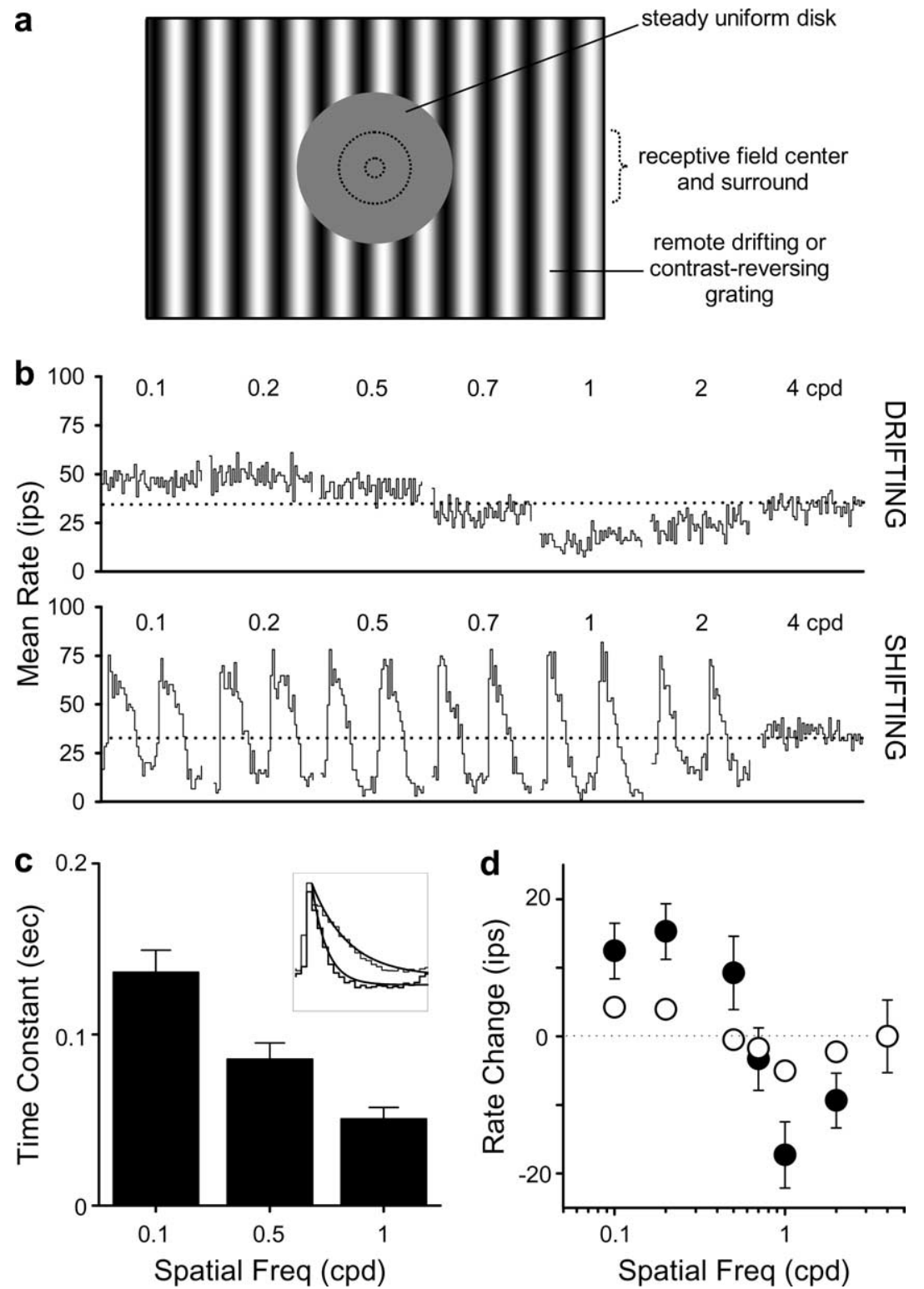

Figure 1. RGC responses to grating patterns moving outside the CRF. $\boldsymbol{a}$, The stimulus consisted of a 30 by 20 deg sinewave grating of a chosen spatiotemporal frequency, the central portion of which was masked by a steady uniform disk of the same mean luminance that covered the center and surround of recorded cells. $\boldsymbol{b}$, Responses of an $0 \mathrm{~N}-\mathrm{Y}$ cell to a 0.5 contrast remote grating of rate of the cell under full-field steady uniform illumination. Disk diameter: 10 deg. c, Mean time constant of single exponential fits to the falling phase of the shift (contrast-reversal) responses of $18 Y$ cells to $0.1,0.5$, and 1 cpd remote gratings. Inset shows example fits of two shift responses. $\boldsymbol{d}$, Change in mean spike rate for drifting gratings and reversing gratings (filled and unfilled symbols, respectively). Error bars indicate SDs. Freq, Frequency.

recorded with grating contrast set to 0.5 and 0 (i.e., no remote stimulus). The third pattern consisted of two drifting sinusoidal gratings one of which exactly replaced the disk (see Fig. $6 a$ ). The central grating drifted at a noninteger multiple of the remote grating frequency to avoid harmonic overlap ( 2 and $5 \mathrm{~Hz}$, respectively). Spatial tuning curves were measured with the central grating by varying its spatial frequency and adjusting its contrast until the Fourier amplitude of the response at the drift frequency fell in the linear range of RGCs [5-10 impulses per second (ips)]. The fundamental response component was then normalized by grating contrast, averaged across three trials of the same spatial frequency, and plotted as magnitude and phase. Spatial tuning curves were collected for the central grating alone and with a 0.5 contrast remote grating of 0.1 and 1 cpd. The data were fit by an extended difference-of-Gaussians model which includes delay, as well as strength and size, terms for the CRF 


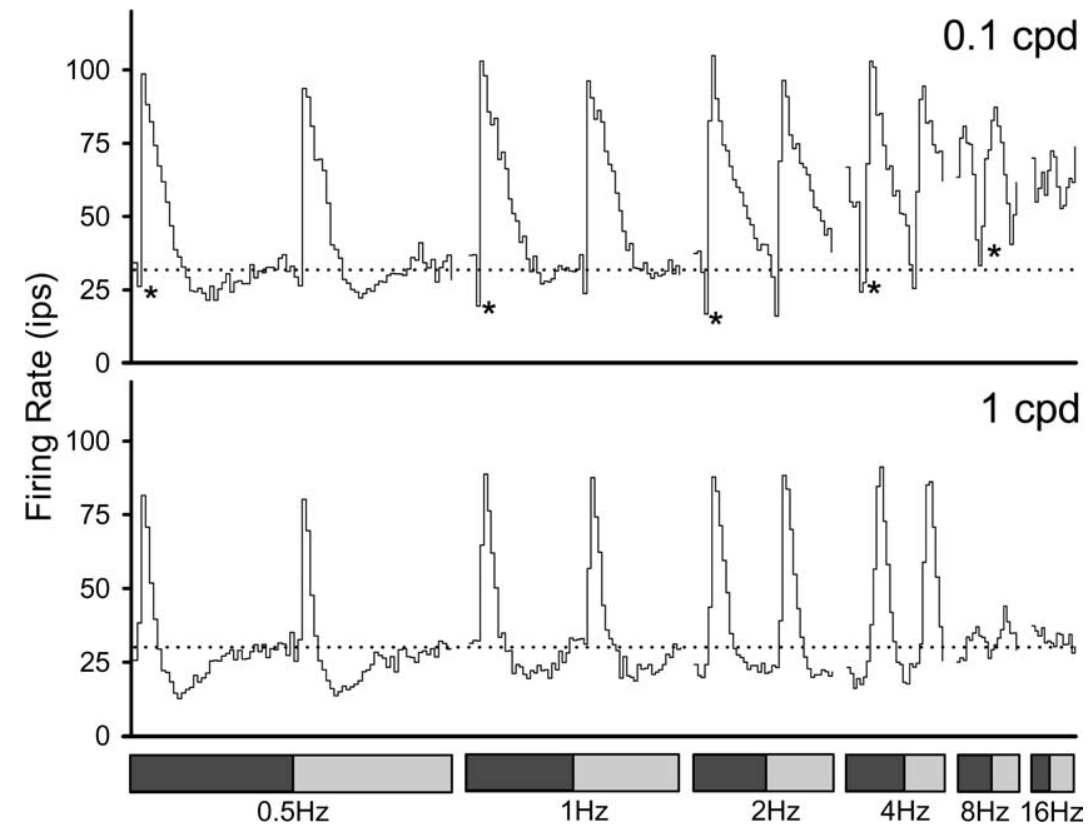

Figure 2. Shift responses to remote gratings are shaped by excitatory and inhibitory mechanisms with different time courses. Plotted are the average responses of eight $0 \mathrm{~N}-\mathrm{Y}$ cells to 0.1 and $1 \mathrm{cpd}$ remote gratings of 0.5 contrast shifting back and forth at various frequencies. Dark-light gray bars illustrate the timing of contrast reversals and are 2, 1, 0.5, 0.25, 0.125, and $0.0625 \mathrm{sin}$ length (from lowest to highest frequency). The corresponding numbers of bins in each record are 80,60,40,30,20, and 15. Dashed lines indicate the average maintained discharge rate of the group under constant full-field illumination. Asterisks mark the downward inflection in rate with low-spatial-frequency gratings.

\section{Ganglion cell responses to remote} drifting and reversing gratings Stimulus motion outside the CRF can have pronounced effects on the firing pattern of cat RGCs. The effect on spiking depends strongly on the spatial and temporal content of the remote stimulus, especially for Y-type cells (Fig. 1). As reported by Passaglia et al. (2001), continuous motion of a low spatial frequency (LSF) pattern $(0.1-0.5 \mathrm{cpd}$ at 1 $\mathrm{Hz}$ ) caused a sustained increase in mean spike rate whereas continuous motion of a high spatial frequency (HSF) pattern (1-2 cpd at $1 \mathrm{~Hz}$ ) caused a sustained decrease in mean rate (Fig. 1b, top). Neither the CRF center nor the surround mechanisms contribute to the mean rate effect, as evidenced by the lack of a modulated component in the records. Sudden motion of a LSF or HSF remote pattern elicited an altogether different response from RGCs (Fig. 1b, bottom). Shifting the spatial phase of a grating pattern by 180 deg (i.e., reversing grating contrast) caused a vigorous burst of spikes regardless of grating spatial frequency (up to $\sim 4 \mathrm{cpd}$ at which point the spatial resolution of the underlying mechanism is usually exceeded). This "shift response," as it is commonly

center, and surround (Frishman et al., 1987). For one-dimensional gratings of fixed drift frequency, the spatial tuning curve $S$ is modeled as $S(v)=S_{\mathrm{c}}(v)+S_{\mathrm{s}}(v)$.

where $v$ is spatial frequency and $S_{\mathrm{c}}$ and $S_{\mathrm{s}}$ are the spatial frequency responses of the center and surround mechanisms, respectively. Expressed in polar notation the model is:

$$
|S(v)| e^{j P(v)}=K_{c} e^{j P_{c}-\left[\pi v R_{c}\right]^{2}}+K_{s} e^{j P_{s}-\left[\pi v R_{s}\right]^{2}},
$$

where $K_{\mathrm{c}}$ and $K_{\mathrm{s}}$ are center and surround strength, $R_{\mathrm{c}}$ and $R_{\mathrm{s}}$ are center and surround Gaussian radii, and $P_{\mathrm{c}}$ and $P_{\mathrm{s}}$ are center and surround temporal phase. For all three stimulus patterns, the mean luminance of the spot, disk, and gratings was the same.

Recorded fibers were classified as ON-center X (ON-X), OFF-center X (OFF-X), ON-center Y (ON-Y), or OFF-center Y (OFF-Y) ganglion cells using standard criteria, including the ratio of first- and second-harmonic response amplitude to full-field reversing gratings of high spatial frequency (Hochstein and Shapley, 1976). The few recorded W cells that did not fit these criteria were excluded from analysis. RGC responses were analyzed by constructing histograms of the average time-varying spike rate during a stimulus cycle. The histograms were constructed from $30 \mathrm{~s}$ epochs of discharge, with a cycle divided into 50 intervals unless stated otherwise. Between epochs the mean spike rate was checked to ensure it resettled to the resting level under uniform illumination. Population results are expressed as mean \pm SD and for most conditions statistical significance was determined by an unpaired Student's $t$ test. Ratiometric measurements were transformed logarithmically before statistical testing.

\section{Results}

The data reported here were collected from 60 RGCs in 13 cats. Receptive fields ranged from 2 to $40^{\circ}$ in retinal eccentricity. Other cells corroborated the reported results but provided incomplete datasets. Largely different subsets of cells contributed to each of the three main experiments presented. known, was observed in every Y cell tested, even for patterns that decreased the mean spike rate when drifted. The shift response waveform was virtually identical for ON- and OFF-Y cells so their data were combined for population analyses. Across the ensemble of Y cells, the peak spike rate was largely independent of spatial frequency (ratio of $1.0-0.1 \mathrm{cpd}$ peaks $=1.03 \pm 0.26$ ). The trough spike rate was significantly lower, however, for HSF gratings (trough ratio $=0.50 \pm 0.29$, $p<0.01)$ so the remote pattern had some influence on shift response waveform. Several X cells (5 of 7) also generated a shift response but theirs were much smaller in amplitude and longer in duration than those of Y cells, as found previously (Barlow et al., 1977; Derrington et al., 1979).

The change in amplitude (peak-to-trough) with spatial frequency coincided with a shortening of shift response duration. The duration was quantified by fitting the falling phase with an exponential function, the time constant of which decreased across the ensemble of cells from $136 \pm 55 \mathrm{~ms}$ to $86 \pm 39 \mathrm{~ms}$ to $51 \pm 28 \mathrm{~ms}$ in switching between $0.1,0.5$, and $1 \mathrm{cpd}$ reversing gratings (Fig. 1c). Each reduction in duration was significant $(p<0.01)$. An interesting consequence of these changes in shift response waveform was that the time integral of the modulated rate for reversing gratings depended on spatial frequency in a manner similar to the mean rate for drifting gratings (Fig. 1d). The mean rate effect was weaker for reversing gratings presumably because retinal regions near zero-crossings (i.e., contrast boundaries) of the grating see little-to-no contrast modulation, whereas the zero-crossings move for drifting gratings and thus all regions get sinusoidally stimulated. The correspondence suggests that the mean effect and the shift effect are related by a common nonlinear mechanism.

That the shift effect drove the firing rate both above and 
below the resting rate prompted further examination of response dynamics. Since HSF gratings appear to activate an inhibitory mechanism when drifted, perhaps the spike burst evoked by these gratings when shifted results not from direct excitation but from withdrawal of inhibition, a phenomenon known as rebound excitation (Mitra and Miller, 2007; Margolis and Detwiler, 2007). Figure 2 plots the average shift response of $8 \mathrm{Y}$ cells to 0.1 (top row) and $1 \mathrm{cpd}$ (bottom row) remote gratings of different reversal frequency. These spatial frequencies were chosen because they preferentially activate the meanincreasing and decreasing mechanisms (see Fig. 1b). At slow reversal frequencies $(<1$ $\mathrm{Hz}$ ), shift responses to both grating patterns consisted of a large transient increase in firing rate followed by a prolonged decrease in rate that recovered to the resting level in approximately a second. The positive (excitatory) response phase was shorter lasting for the HSF grating and the negative (inhibitory) phase was more prominent. Since the spike rate recovered to the resting rate between stimulus cycles and was not inhibited, it is unlikely that shift responses to HSF patterns are due to rebound excitation.

Varying reversal frequency revealed additional response features. First, shift responses to LSF gratings were often preceded by a momentary drop in rate lasting $\sim 16 \mathrm{~ms}$ on average (asterisks). This initial pause in activity was not seen with HSF gratings. Second, the latency of the shift response was shorter (16 $\pm 4 \mathrm{~ms})$ for LSF gratings. This is most apparent for the $4 \mathrm{~Hz}$ condition in the figure because of the finer time scale. And thirdly, the shift response disappeared at high reversal frequency $(>8 \mathrm{~Hz})$. The disappearance coincided with overlap in the positive and negative responses phases, which for the $0.1 \mathrm{cpd}$ grating resulted in a large maintained increase in firing rate as seen with drifting LSF gratings (Fig. 1b). The phenomenon has been attributed to asynchronous summation of frequency-doubled signals from many small nonlinear subunits that are distributed widely across the retina (Derrington et al., 1979). This explanation does not, however, account for the $1 \mathrm{cpd}$ grating data. Although the positive response phase was generally larger than the negative phase, the mean rate did not increase at high reversal frequencies. Instead, the shift response was abolished altogether.

\section{Receptive field center stimulation suppresses responses to remote gratings}

Under natural conditions both the CRF and ECRF are visually stimulated. The effect of CRF stimulation on remote grating responses was examined by modulating the luminance of a small
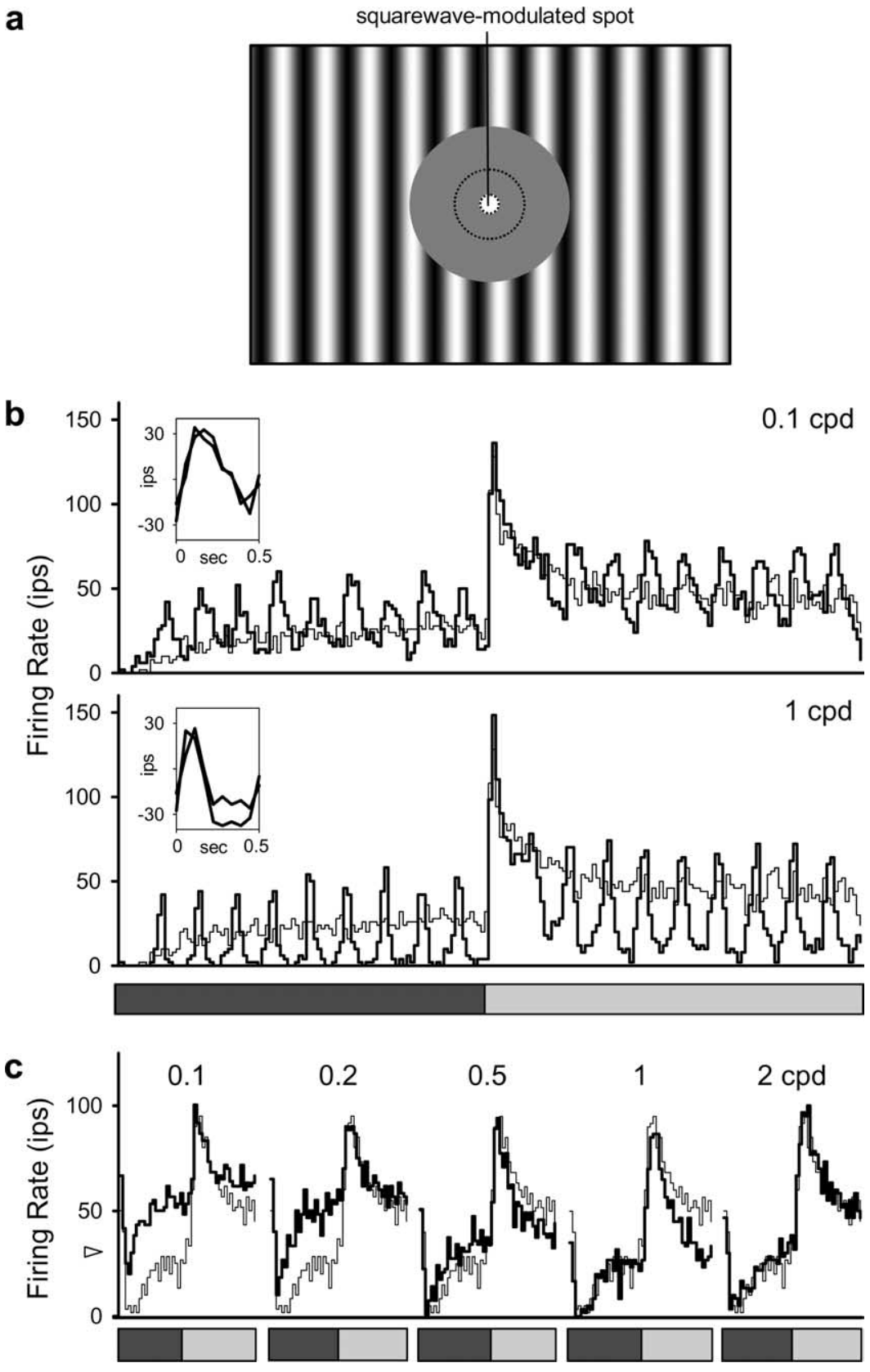

Figure 3. Interaction between RGC responses to local and remote stimuli. $\boldsymbol{a}$, The CRF center was probed with a small spot that periodically stepped up and down in contrast while the ECRF was stimulated with a remote drifting or contrast-reversing grating. $\boldsymbol{b}$, Thin lines are identical in the upper and bottom and plot the response of an $0 \mathrm{~N}-\mathrm{Y}$ cell to a 0.5 contrast spot square wave modulated at $0.1 \mathrm{~Hz}$ on a constant full-field background. Thick lines plot the response of the cell to 0.1 and 1 cpd remote gratings reversing at $1 \mathrm{~Hz}$ during spot stimulation. Insets show the average of the final eight shift responses during positive contrast steps and during negative steps. Number of bins in the main and inset waveforms: 200 and 10. $c$, Thin lines are identical and plot the response of another $0 \mathrm{~N}-\mathrm{Y}$ cell to a 0.2 contrast spot square wave modulated at $1 \mathrm{~Hz}$ on a constant full-field background. Thick lines plot the response to the same spot in the presence of remote gratings of various spatial frequency drifting at $2.5 \mathrm{~Hz}$. The arrowhead marks the maintained discharge rate of the cell. Gray bars illustrate the timing of spot contrast steps and are 10 s in length in $\boldsymbol{b}$ and $1 \mathrm{~s}$ in c. Spot and disk diameters: 0.5 and $10 \mathrm{deg}$. Grating contrast: 0.5 . Measured diameters of the center and surround were 0.8 and $3.7 \mathrm{deg}$, respectively, for cell in c.

spot overlying the CRF center while reversing the contrast of a remote grating (Fig. 3a). The output of a typical ON-Y cell to this stimulus is illustrated in Figure $3 b$. Plotted with thin lines is the average response to a $0.1 \mathrm{~Hz}$ square-wave-modulated spot of 0.5 contrast presented by itself. After each contrast step the spike rate rapidly increased or decreased and then decayed to a plateau level. The decay in rate reflects the action of adaptive mechanisms 
a
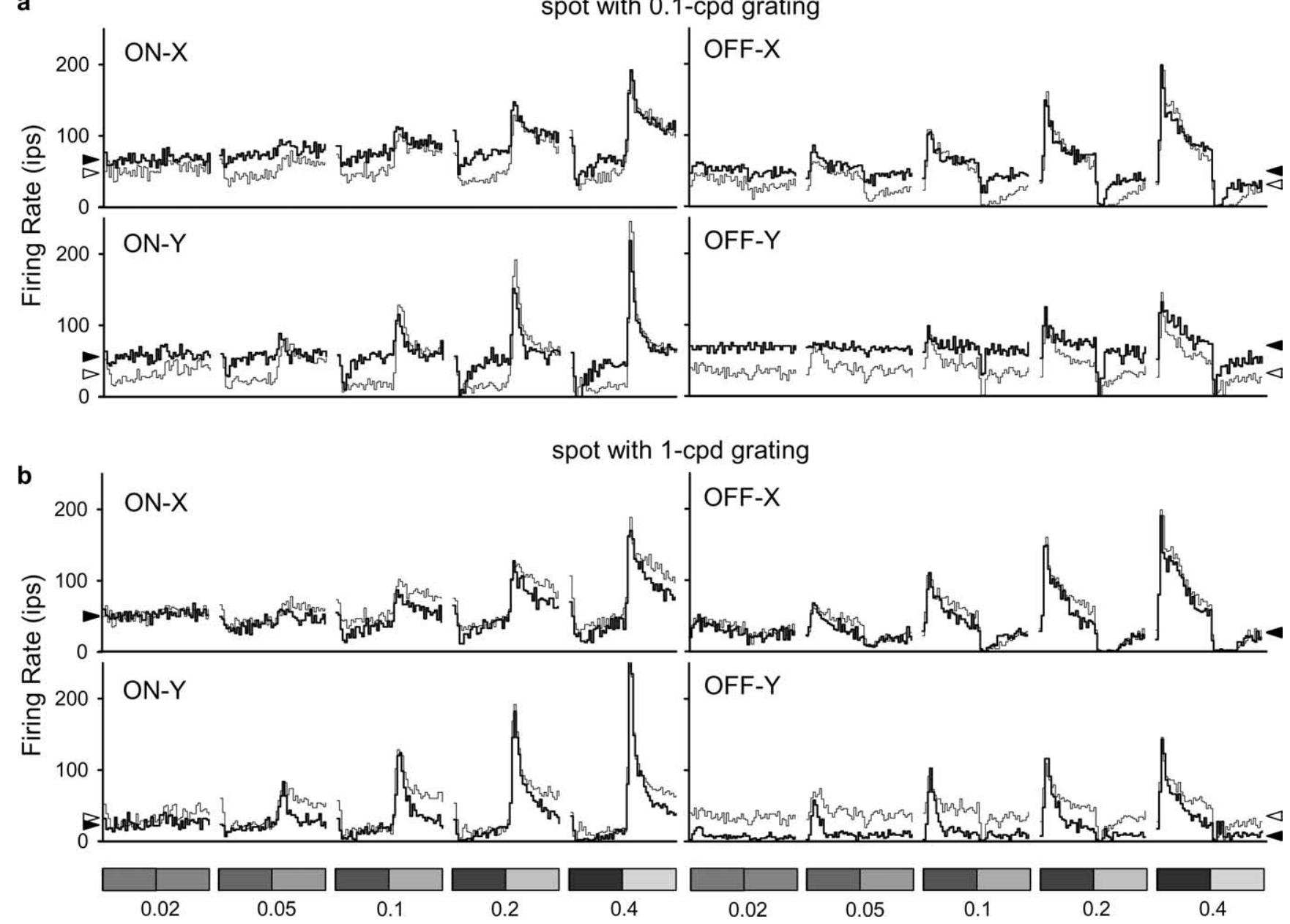

Figure 4. LSF and HSF remote gratings differentially modulate responses of multiple RGC types to preferred and antipreferred contrast steps. Thick lines in $\boldsymbol{a}$ and $\boldsymbol{b}$ plot the response of an ON-X, OFF-X, ON-Y, and OFF-Y cell to square-wave-modulated spots of increasing contrast in the presence of a 0.1 and a 1 cpd remote drifting grating, respectively. Thin lines plot the cells' responses to the same spots on a steady uniform background for comparison. Grayscale bars illustrate the timing of spot contrast steps and are representative of $1 \mathrm{~s}$ in duration. Spot diameter: $0.5(X), 1(0 \mathrm{~N}-Y)$, or $1.5 \mathrm{deg}(\mathrm{OFF}-\mathrm{Y})$; disk diameter: 10 (X, OFF-Y) or $15 \mathrm{deg}(\mathrm{ON}-\mathrm{Y})$; grating contrast and drift frequency: 0.5 and $2.5 \mathrm{~Hz}$; measured center and surround diameters: 0.4 and $4.2 \mathrm{deg}$ ( $0 \mathrm{~N}-\mathrm{X}$ ), 0.7 and $2.5 \mathrm{deg}$ $(\mathrm{OFF}-\mathrm{X}), 1.1$ and $17.8 \mathrm{deg}(\mathrm{ON}-\mathrm{Y})$, and 1.8 and $7.0 \mathrm{deg}(\mathrm{OFF}-\mathrm{Y})$. Unfilled arrows indicate the maintained discharge rate of the cells. Filled arrows indicate their mean spike rate to the remote grating by itself. For the $X$ cells in $\boldsymbol{b}$, the arrows overlay completely.

in the CRF center. Plotted with thick lines is the average response to a 0.1 and $1 \mathrm{cpd}$ remote grating reversing at $1 \mathrm{~Hz}$ during spot stimulation. At spot onset and offset, the shift response is greatly reduced in amplitude for both gratings, and recovers in $\sim 1 \mathrm{~s}$ to a sustained level that is independent of spot luminance for the LSF grating and probably also for the HSF grating if the shift response had not been clipped by spike threshold (insets). The impact of the spot is especially apparent for the HSF grating because of the prominent negative component of its shift responses. The recovery of this component following spot onset approximately follows the decay time of the spot response. The shift responses of all seven Y cells tested in this manner were strongly suppressed at spot onset and offset and were similar in magnitude at other times (except one $\mathrm{ON}$ cell for which shift responses were larger than baseline during the positive contrast step and smaller during the negative step).

\section{Remote gratings of low and high spatial frequency modify center response dynamics}

Just as CRF stimulation can alter RGC responses to remote gratings so too can remote gratings modify RGC responses to CRF stimuli. Figure $3 c$ shows that the affected features depend on the spatial frequency of the grating pattern. Plotted with thin lines is the average response of an ON-Y cell to a small spot centered on the CRF. The spot was square wave modulated at $1 \mathrm{~Hz}$ and 0.2 contrast. Like most ON cells, darkening the spot (antipreferred contrast step) transiently decreased the spike rate, which then recovered back to the resting level (arrowhead). Conversely, brightening the spot (preferred contrast step) increased the spike rate, which decayed to a plateau level above the resting rate. Plotted with thick lines are the cell's responses to the same spot as gratings of various spatial frequency drifted in the ECRF. Remote LSF gratings $(0.1$ to $0.2 \mathrm{cpd})$ increased the mean rate and decreased the time variation in rate, with preferred step responses appearing relatively unaffected compared with antipreferred step responses. Remote HSF gratings $(<2-4 \mathrm{cpd})$ also decreased the time-variation in rate but in the opposite manner. The nonpreferred response phase was largely spared while the plateau rate of the preferred phase was reduced. HSF gratings often lowered the mean spike rate as well, although not for this RGC. The disparate effects of remote LSF and HSF gratings on center response dynamics suggest that they are mediated by separate retinal pathways.

The interaction between local gain controls driven by the spot 

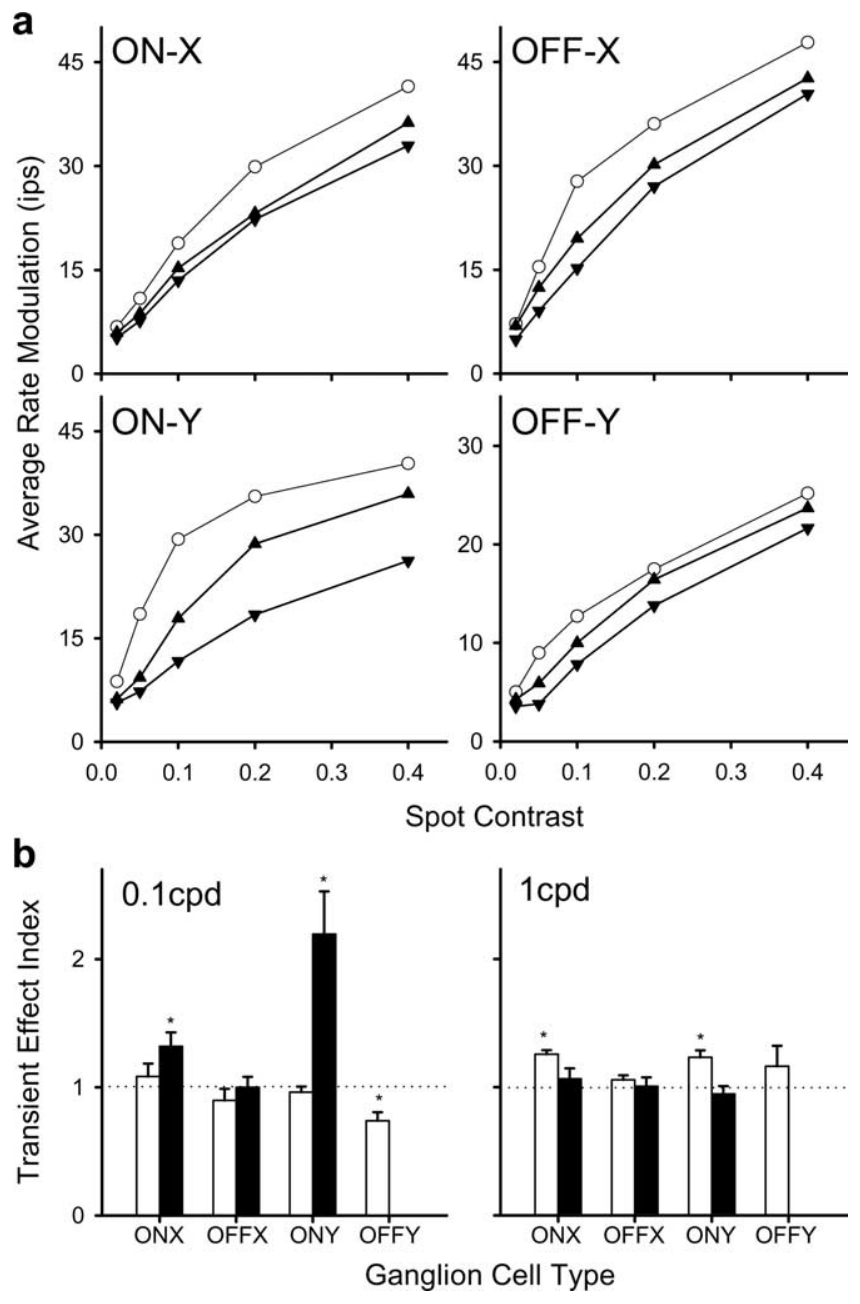

Figure 5. Remote stimulation enhances the transientness of RGC responses while suppressing their overall responsiveness. $\boldsymbol{a}$, Plotted versus spot contrast is the average modulation of firing rate of the cells in Figure 4 over a cycle of spot stimulation for the spot alone (circles) and the spot with remote grating (downward triangles, $0.1 \mathrm{cpd}$; upward triangles, $1 \mathrm{cpd}$ ). The modulation measure is independent of spot response waveform and given by the integral of the absolute deviations of the time-varying firing rate from the unmodulated rate for each stimulus condition (i.e., the between the solid and dashed lines in Fig. $4 a-c)$. Both remote gratings suppressed the overall response across the ensemble of recorded cells ( 5 ON-X, 5 OFF- $X, 15$ ON-Y, 10 OFF-Y). $\boldsymbol{b}$, Average index values of the transient effect on responses of different RGC types to preferred (unfilled bars) and antipreferred (filled bars) contrast steps. The transient effect index was defined as the peak-minus-plateau firing rate for the spot with the remote grating divided by the peak-minus-plateau rate for the spot alone. An index of one (dashed line) indicates no effect. No filled bars are shown for OFF-Y cells because their low mean rate clipped responses at zero rate. Error bars are SEs, and asterisks indicate statistical significance after log transformation at a level of 0.05 .

and global gain controls driven by remote gratings was further examined by varying spot contrast. Figure 4 plots with thin lines the spot responses of an ON-X, OFF-X, ON-Y, and OFF-Y cell. Increasing contrast made preferred step responses of all cells larger and more transient. Changes in the response to antipreferred steps were less apparent because the rate modulation was small or truncated by spike threshold. The thick lines in Figure 4, $a$ and $b$, plot the spot response of these cells in the presence of a 0.1 and $1 \mathrm{cpd}$ remote drifting grating, respectively. The modulated response of all cell types was reduced by the gratings (Fig. 5a), as measured by the average absolute deviation of the time-varying rate from the mean rate (Fig. 4, arrowheads) for each stimulus condition. The average reduction for a 0.2 contrast spot was between 20 and 35\% across the population of cells and was statistically indistinguishable for the LSF and HSF gratings (ON-Y: $33.6 \pm 13.6$ and $24.6 \pm 12.5$, OFF-Y $22.7 \pm 23.2$ and $21.1 \pm 13.1, \mathrm{ON}-\mathrm{X} 31.5 \pm 6.4$ and $32.5 \pm 18.4$, OFF-X $34.6 \pm$ 13.5 and $26.5 \pm 13.3$, respectively). The LSF grating brought about the reduction by acting primarily on the antipreferred response phase while the HSF grating did so by targeting the preferred phase. OFF-Y cells were often an exception in that both phases were altered.

Inspection of the ensemble of spot response waveforms revealed several notable aspects of the remote effect on RGC responsiveness, which can be seen in these records. First, although the overall response modulation was reduced, the LSF grating had the effect of enhancing the transient component of the antipreferred step response of many ON cells (15 of 20), especially $\mathrm{ON}-\mathrm{Y}$ cells. This was possible because the grating increased mean spike rate while concurrently suppressing the plateau rate. It even imparted six cells, such as the illustrated ON-Y cell, with an antipreferred step response that they otherwise lacked. The effect was quantified in terms of a "transient index" (Fig. 5b), which was defined for preferred steps as the ratio of the peak-minus-plateau rates with and without remote gratings (or trough-minusplateau for antipreferred steps). The transient index for the antipreferred phase was greater than one for ON-Y cells, indicating that the LSF grating made the transient response larger relative to the sustained response. This was not true for the preferred phase of ON cells or either phase of OFF cells (index was actually less than one for OFF-Y cells). Second, although the LSF grating raised the mean rate, the time-varying firing rate was nearly identical for the preferred step response ( 24 of 35 cells, 7 exceptions being OFF-Y cells). This implies that the excitatory signal from the spot combines nonlinearly with the maintained excitation produced by the remote stimulus. If the signals summed linearly within the retina, spike rate should have been elevated during the preferred phase as well. And thirdly, the HSF grating lowered the plateau rate of preferred step responses while minimally altering the peak rate ( 27 of 35 cells). This had the effect in ON cells of enhancing the transient component of preferred step responses (Fig. 5b), again implying a nonlinear interaction between local and remote inputs to RGCs. Hence, signals from the CRF and ECRF combine in complex manner that has significant contrastdependent effects of RGC response properties.

\section{Remote gratings of low spatial frequency strengthen ganglion cell spatial bandpass tuning}

Since remote stimulation can alter the temporal response properties of cat RGCs, perhaps it affects their spatial response properties as well. To assess the possibility, the CRF was probed with a low-contrast grating while the ECRF was either uniformly illuminated or stimulated with a high-contrast grating (Fig. $6 a$ ). The central grating drifted at $2 \mathrm{~Hz}$ and the remote grating drifted at a nonharmonic frequency of the central grating to further mitigate against response contamination by the remote stimulus. Figure $6 b$ plots the spatial frequency response of an ON-X cell measured without (left) and with a 0.1 and 1 cpd remote grating (right). Cell responsivity was quantified by normalizing the first harmonic (F1) amplitude of the response to the central grating by grating contrast. It can be seen that the LSF remote grating strongly suppressed responsivity to LSF central gratings, making the tuning curve more bandpass in shape. This was not a byproduct of the grating patch diameter, which becomes smaller than the spatial period of the central grating at very LSF, because the same patch was used for both datasets. For nearly every RGC studied (20 of 
a
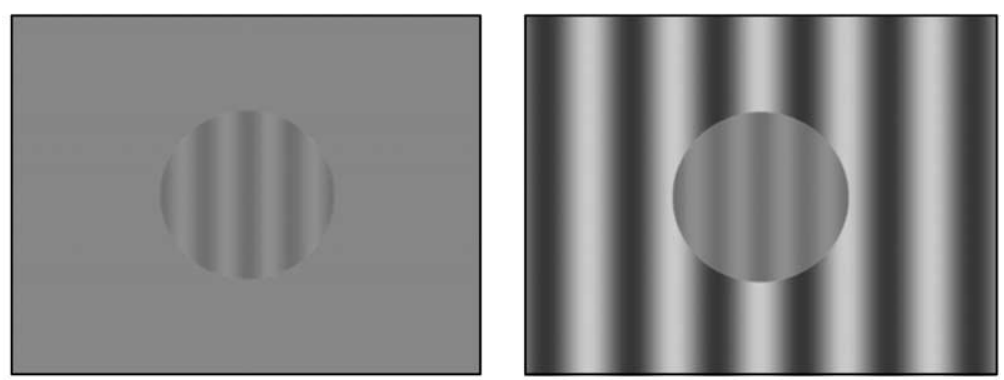

b

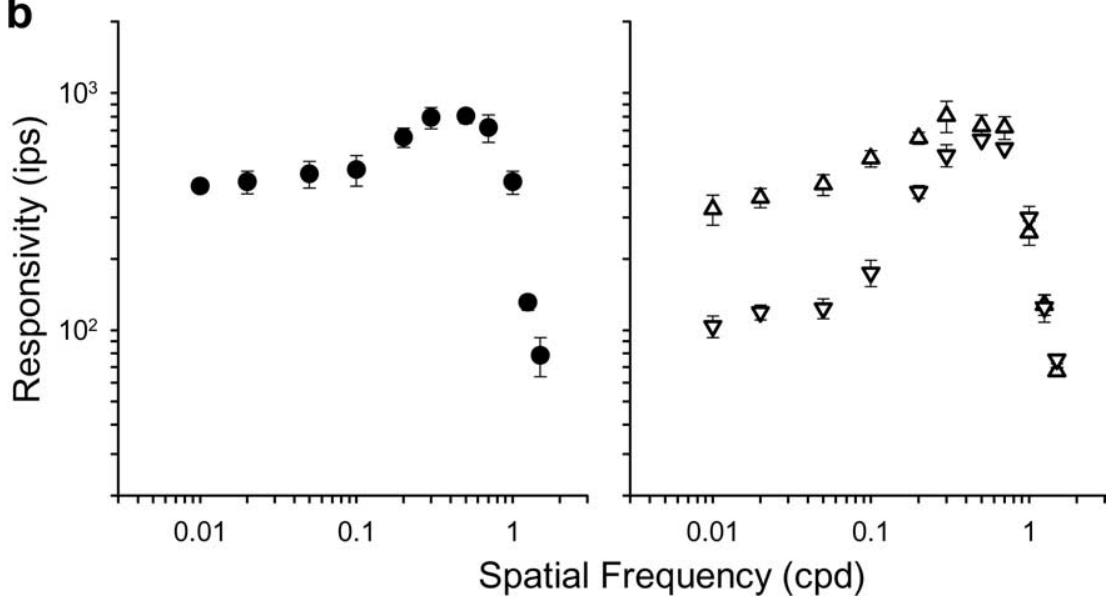

Figure 6. Remote LSF gratings suppress RGC responses to LSF patterns. $\boldsymbol{a}$, The CRF was probed with a drifting grating constrained to a circular patch that covered the center and surround while the ECRF was uniformly illuminated (left) or stimulated with a remote grating drifting at a nonharmonic frequency of the central grating (right). $\boldsymbol{b}$, Spatial frequency response of an $0 \mathrm{~N}-\mathrm{X}$ cell for a $2 \mathrm{~Hz}$ central grating presented by itself (left) and with remote gratings (right) of 0.1 and $1 \mathrm{cpd}$ (downward and upward triangles, respectively). Responsivity is defined as the magnitude of the Fourier component at the drift frequency divided by grating contrast. Error bars are SDs of three responsivity measurements. Patch diameter: 10 deg. Remote grating contrast and temporal frequency: 0.5 and $5 \mathrm{~Hz}(0.1 \mathrm{cpd})$ or $0.2 \mathrm{~Hz}(1 \mathrm{cpd})$.

23) spatial bandpass tuning was measurably enhanced. Examples of an ON-X, OFF-X, ON-Y, and OFF-Y cells are provided in Figure 7. The response suppression observed with gratings was much greater than that with spot stimulation. F1 amplitude was reduced by a factor of $2.8 \pm 1.4$ in Y cells and $2.6 \pm 0.5$ in X cells for a 0.2 cpd central grating compared with the 0.2 - to 0.4 -fold reduction for a center spot (Fig. 5). The small difference between these two cell types was not significant. In addition to suppressing responsiveness, the LSF remote grating tended to phase advance the response. It can also be seen in Figure $6 b$ that the HSF remote grating had little, if any, impact on the spatial tuning curve. Four other cells were tested with HSF gratings, and none showed a marked effect. Since the HSF mechanism prefers low drift frequencies (Passaglia et al., 2001), perhaps the remote grating moved too fast for it to suppress responsivity like LSF gratings. This possibility was not investigated.

The spatial frequency tuning effects imply that remote stimulation alters the CRF profile of RGCs. To assess whether center or surround shape, strength, latency, or combinations thereof were modified, response amplitude and phase data were collectively described with an extended difference-of-Gaussians model (see Materials and Methods). Lines in Figure 7 illustrate the spatial frequency response of the best-fitting model, and Table 1 gives model parameter values. The similar radius entries for each cell highlight a general finding, which is that the LSF remote grating had little impact on CRF center and surround size. The similar low- and high-frequency cutoffs in Figures 6 and 7 suggest this, and indeed the mean square error of tuning curve fits increased by $<10 \%$ for most cells ( 20 of 23 ) if the radii parameters were fixed for the two stimulus conditions. Figure $8 a$ plots estimates of CRF strength and phase parameters for the ensemble of $\mathrm{ON}$ and OFF cells without the LSF remote grating versus with it. On average, center and surround strength was reduced by $26 \pm 16 \%$ and $8 \pm 40 \%$, while center and surround phase was advanced by $30 \pm 20$ deg and $37 \pm 31 \mathrm{deg}$, respectively. Except for surround strength the changes were all significant (paired $t$ test, $p<0.01$ ). The 0.26 -fold reduction in center strength is consistent with that seen for the center spot, implying that the spatial tuning effects reflected a change in center-surround relationship. This can be seen in Fig. $8 b$ as center-surround balance tipped more toward the surround $(\mathrm{Kc} / \mathrm{Ks}$ below equality line) and in Figure $8 c$ as the surround adopted a more antagonistic phase (180deg opposite) with respect to the center (Ps - Pc above equality line). Hence, remote stimulation enhanced spatial bandpass tuning in RGCs by altering the relative weighting and timing of center and surround signals within the CRF. CRF size was for the most part unaltered.

\section{Discussion}

Stimulation of the ECRF is reported to elicit various nonlinear effects on RGCs, some of which seem paradoxical, such as background motion which can excite or inhibit cells depending on whether the movement is sudden or smooth. Our results confirm within a single study the multiplicity of remote effects and show that it stems in part from a complex dependence on the spatiotemporal pattern of illumination. Six findings are described. First, a shift in background pattern elicits a burst of action potentials in cat $\mathrm{Y}$ cells regardless of the spatial content of the pattern, as previously observed, and after the burst the spike rate is strongly suppressed for HSF patterns. The suppression shortens shift response duration and is presumed to underlie mean-rate decreases produced by drifting HSF patterns. Second, at high contrast-reversal frequencies, shift responses transform into a sustained rate increase for LSF remote patterns but disappear for HSF patterns. Third, shift responses are driven by excitatory input onto RGCs and are not rebound responses to the termination of hyperpolarizing input. Fourth, local and remote signals combine within the retinal circuitry in a complicated and generally nonlinear manner. For example, shift responses were blocked during onset and offset of a spot presented within the CRF, yet summed linearly with the spot response at other times. Also, remote-drifting patterns tonically raised or lowered the mean spike rate, yet for portions of the spot response the time-varying rate was unchanged. Fifth, spot responses of $\mathrm{X}$ and $\mathrm{Y}$ cells are modulated by remote mechanisms that are differentially sensitive to LSF and HSF patterns. Both patterns make responses more transient by respectively reducing the sustained rate to preferred or antipreferred contrast steps. The pathway of modulation is likely the inner plexiform layer 


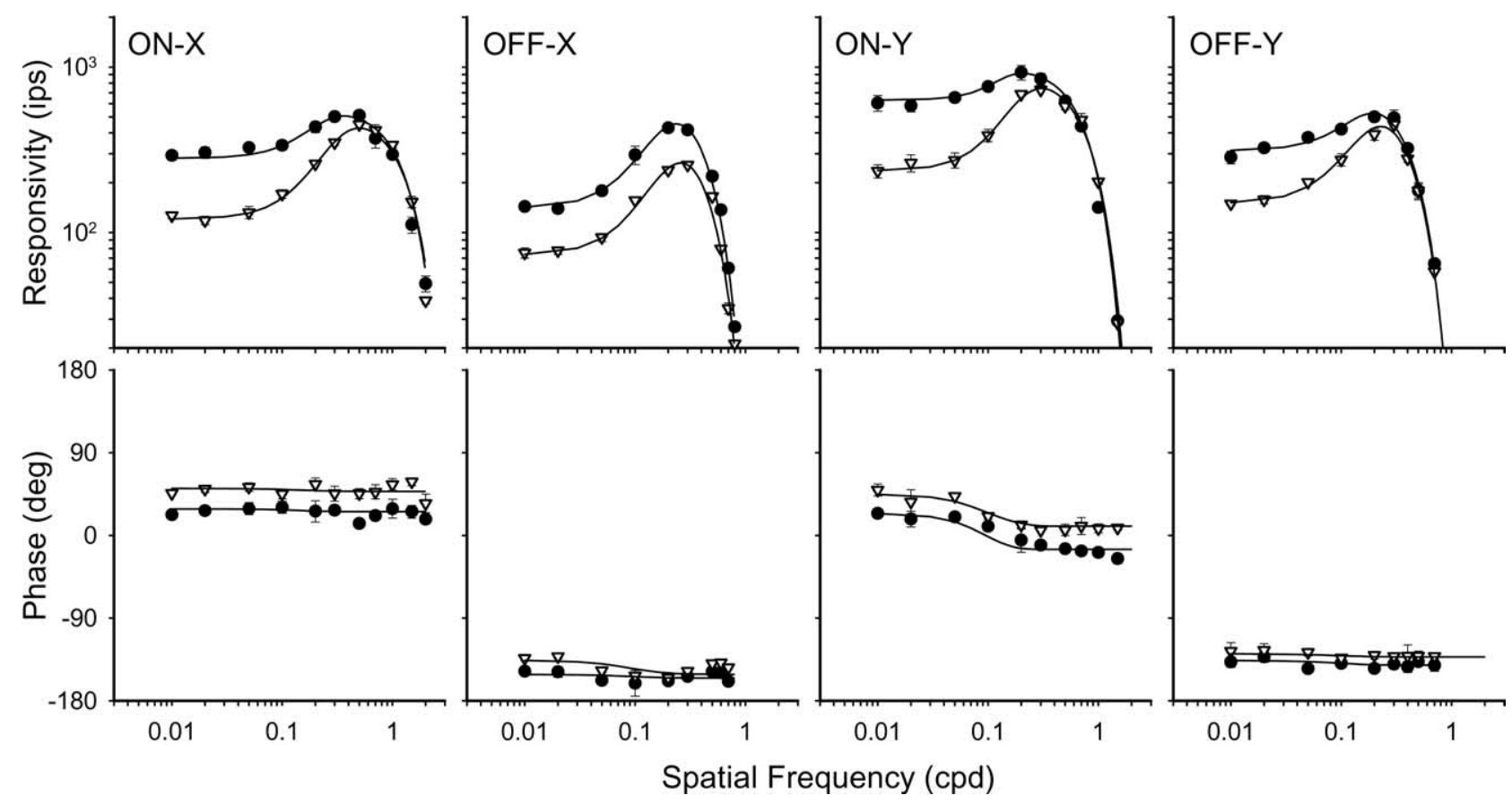

Figure 7. Remote LSF gratings strengthen the spatial bandpass tuning and advance the response phase of multiple RGC types. Symbols plot the spatial frequency responses (amplitude and phase) of an $0 \mathrm{~N}-\mathrm{X}, 0 \mathrm{FF}-\mathrm{X}, \mathrm{ON}-\mathrm{Y}$, and $0 \mathrm{FF}-\mathrm{Y}$ cell for a $2 \mathrm{~Hz}$ central grating presented by itself (filled) and with a 0.1 cpd remote grating of 0.5 contrast drifting at $5 \mathrm{~Hz}$ (unfilled). Error bars are SDs of three responsivity measurements. Patch diameter: $10 \mathrm{deg}$. Solid lines are best fits of an extended difference-of-Gaussians model to the data (see Materials and Methods). Estimates of model CRF parameters are given in Table 1.

since $\mathrm{ON}$ and OFF cells are affected during opposite response phases. An outer retinal pathway is also unlikely because horizontal cells do not respond to HSF gratings (Zaghloul et al., 2007). And sixth, remote LSF patterns enhance the spatial bandpass tuning of $\mathrm{X}$ and $\mathrm{Y}$ cells by shifting centersurround balance and temporal phase so that the surround becomes more antagonistic.

Table 1. Estimates of model receptive field parameters for cells in Figure 7

\begin{tabular}{|c|c|c|c|c|c|c|c|c|}
\hline & \multicolumn{2}{|l|}{ ON-X } & \multicolumn{2}{|l|}{ OFF-X } & \multicolumn{2}{|l|}{ ON-Y } & \multicolumn{2}{|l|}{ OFF-Y } \\
\hline & - remote & + remote & - remote & + remote & - remote & + remote & - remote & + remote \\
\hline$K_{\mathrm{c}}$ (ips) & 628 & 576 & 878 & 709 & 1092 & 846 & 881 & 728 \\
\hline$K_{s}$ (ips) & 349 & 576 & 797 & 660 & 672 & 683 & 572 & 574 \\
\hline$R_{\mathrm{c}}(\mathrm{deg})$ & 0.3 & 0.3 & 0.8 & 0.8 & 0.5 & 0.4 & 0.8 & 0.8 \\
\hline$R_{s}($ deg $)$ & 1.1 & 1.0 & 1.6 & 1.3 & 2.0 & 2.2 & 1.8 & 1.8 \\
\hline$P_{c}($ deg $)$ & 8 & 42 & 145 & 169 & -10 & 8 & -148 & -135 \\
\hline$P_{s}($ deg $)$ & 169 & -140 & -35 & -17 & 138 & 175 & 27 & 43 \\
\hline
\end{tabular}

\section{The extraclassical receptive field}

The nonclassical receptive field of RGCs is the area of space wherein stimuli can evoke responses not attributable to center or surround mechanisms, which are classically defined to be linear (Rodieck, 1965). Since CRF mechanisms might not behave linearly for all inputs, our study focused on the ECRF to facilitate data interpretation, which means that nonlinear mechanisms underlying reported phenomena could extend into the CRF as well. Based on mean rate effects of remote drifting gratings, we previously deduced that the ECRF contains pools of large excitatory subunits and small inhibitory subunits (Passaglia et al., 2001). We also posited that a third subunit pool must exist as neither mean-changing subunit had both the right size and polarity to mediate shift effects to HSF patterns. This reasoning assumed that remote stimuli produce excitatory shift responses, like fullfield stimuli (Hochstein and Shapley, 1976), but this was not certain as most previous studies in cat used LSF remote patterns (Krüger and Fischer, 1973; Barlow et al., 1977, Derrington et al., 1979), and a study in rabbit described potent shift inhibition using natural scenes that could be masked by simultaneous CRF stimulation (Roska and Werblin, 2003).

In this study, remote spatial frequency was varied and three shift-response components were identified. The first is a small initial drop in spike rate lasting $10-20 \mathrm{~ms}$ that is apparent only for LSF gratings. Ironically, this component was predicted by dynamical models of retinal contrast gain control although it was not actually seen (Victor, 1987, 1988). The reason for its absence, given our results, is that only HSF gratings had been used for experimental testing. The second and third components are a sharp jump in spike rate followed by a prolonged depression. While the observed rate decrease could be attributed to the small inhibitory subunits, neither they nor the large excitatory subunits can account for the rate increase for HSF remote gratings, so a pool of small excitatory subunits still seems necessary. The shift excitation could come directly from amacrine cells through gap junctions connecting the cells to each other and to $\alpha(\mathrm{Y})$ ganglion cells (Vaney, 1994; Xin and Bloomfield, 1997). It could also come indirectly, in whole or in part, via disinhibition of bipolar cells given that most amacrine cells employ inhibitory neurotransmitters (Marc et al., 1998). The latter is the presumptive pathway for $\mathrm{X}$ cells that show a shift effect, since $\beta$ ganglion cells do not form gap junctions with amacrine cells (Vaney, 1994).

A biophysical model of CRF microcircuitry gives insight into what the various nonlinear subunits might be (Hennig et al., 2002). The core of the model is a disinhibitory circuit found in salamander retina wherein narrow-field amacrine cells inhibit 
a
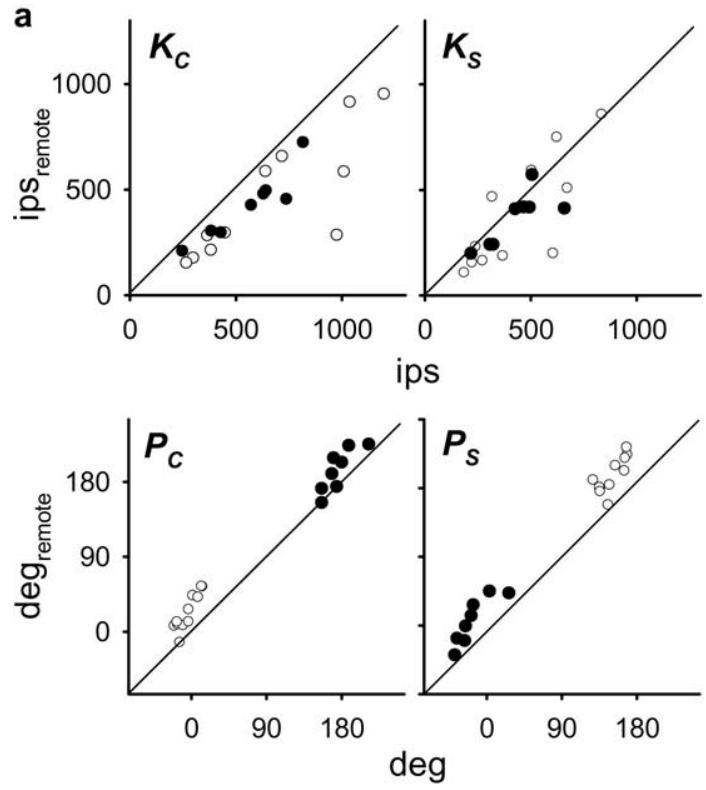

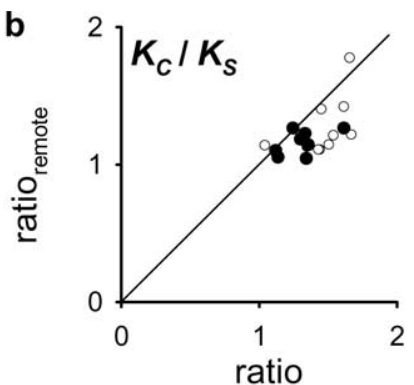

C

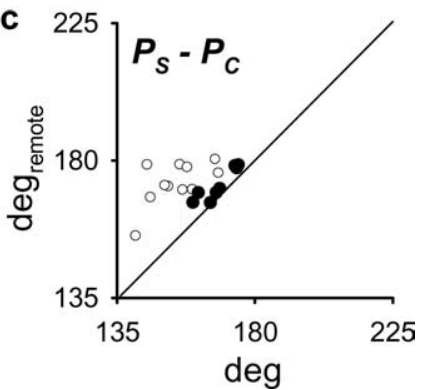

Figure 8. Changes in CRF properties underlying the remote effect on spatial bandpass tuning. $\boldsymbol{a}$, Model estimates of CRF center and surround strength $\left(K_{c}\right.$ and $\left.K_{s}\right)$ and phase $\left(P_{c}\right.$ and $\left.P_{s}\right)$ for the ensemble of recorded ON and OFF cells (unfilled and filled symbols, respectively) to a $2 \mathrm{~Hz}$ central grating with and without a $0.1 \mathrm{cpd}$ remote grating of 0.5 contrast drifting at $5 \mathrm{~Hz}$. Center and surround radii $\left(R_{c}\right.$ and $\left.R_{s}\right)$ were constrained to be equal for the two stimulus conditions. $\boldsymbol{b}, \boldsymbol{c}$, Center-surround strength ratio and phase difference calculated from parameter estimates. Patch diameter: $10-15 \mathrm{deg}$.

local bipolar cells and form mutual inhibitory connections with wide-field amacrine cells (Roska et al., 1998). Completing the circuit is a realistic description of photoreceptor output and intraretinal connectivity between major cell classes. Model simulations implicated photoreceptors as the main source of nonlinearity within the CRF and the larger CRF of Y cells as the reason for their more nonlinear behavior. The nested amacrine circuit played a weaker role, but the simulations did not include an ECRF so the circuit was constrained in space. Judging from its simulated behavior, we think a mosaic of such circuits coupled via the wide-field amacrine cells could capture much of our results and others (supplemental Figure, available at www. jneurosci.org as supplemental material). The key insight from the Hennig et al. model is that wide-field amacrine output is dominated at LSF by linear inputs from sustained bipolar cells and at HSF by nonlinear inputs from transient bipolar cells. Depending on the remote pattern the linear and nonlinear signals should sum in-phase or out-of-phase within and across wide-field amacrine cells and result in mean effects and shift effects in RGCs having the observed spatiotemporal relationships (supplemental Figure legend, available at www.jneurosci.org as supplemental material). If this is validated computationally, the meandecreasing, mean-increasing, and shift subunits would respectively correspond to narrow-field amacrine, wide-field amacrine, and bipolar cells.

\section{Retinal integration of local and global signals}

The ECRF of RGCs is thought to be important for saccadic masking (Noda and Adey, 1974; Solomon et al., 2006), contrast gain control (Shapley and Victor, 1978; Enroth-Cugell and Jakiela, 1980; Solomon et al., 2006), and segregation of figure-ground motion during natural viewing (Passaglia et al., 2001; Greschner et al., 2002; Olveczky et al., 2003). These tasks all involve retinal integration of local and global signals and the product in each case is suppression of one signal by the other. Our results and

those cited above demonstrate that the suppressive effect is complex and not fully captured by linear measures like first harmonic amplitude. The sustained response to CRF stimulation is attenuated more strongly than the transient, especially in ON cells. A sustained component-specific effect was noted previously in cat and involved GABAergic inhibition (EnrothCugell and Jakiela, 1980; Frishman and Linsenmeier, 1982). The effect was also seen intracellularly in guinea pig but was stronger for OFF cells (Zaghloul et al., 2007). Moreover, we show that the suppression amount depends systematically on remote spatial frequency and is asymmetric for preferred and antipreferred contrast steps. LSF patterns target the antipreferred response phase of ON and OFF cells while HSF patterns target the preferred phase, suggesting that RGC responses do not simply reflect increments and decrements in input from either the ON or the OFF pathway. If this were true, both response phases should have been affected since the remote mechanism is tonically active with drifting gratings. Instead, the result implies that RGC responses get input directly or indirectly from both ON and OFF pathways, as evidence increasingly indicates (Belgum et al., 1982; Chen and Linsenmeier, 1989; Zaghloul et al., 2003), and the pathways are differentially targeted by the remote mechanism depending on the remote stimulus. A definitive conclusion cannot be made from spike recordings as the firing rate is often rectified for antipreferred contrast steps, which makes the input waveform to the spiking mechanism uncertain. The phase-specific effects we see on response dynamics could thereby be manifestations of the interaction of spike threshold with subthreshold signals, which get hidden or revealed via tonic changes in gain and RGC membrane potential caused by remote stimulation (Zaghloul et al., 2007). While this possibility cannot be excluded, it would require rather tight coupling between retinal mechanisms controlling the mean rate and the modulated rate in order for one to nearly exactly compensate for changes in the other so that the preferred response phase would appear unchanged.

It is well established that adaptive processes operate within the CRF to suppress sustained responses of RGCs, as our spot data can attest, and they have been modeled as a local contrast gain control (Victor, 1987, 1988). Global gain controls activated here by ECRF stimulation also suppress the sustained component, making responses even more transient. They do so by altering the relative phase and strength of CRF mechanisms such that the surround becomes more antagonistic to the center. CRF size is unaffected, consistent with another study (Solomon et al., 2006). RGCs apparently differ in this respect from lateral geniculate cells where size changes are first reported (Nolt et al., 2004, 2007). A consequence of the center-surround alterations is greater spatial bandpass tuning in high-contrast LSF environments. This makes functional sense since the system can afford to be discriminatory when signal power is abundant. Hence, RGCs may behave like spatial contrast discriminators or general object detectors as background illumination dictates. 


\section{References}

Angelucci A, Bressloff PC (2006) Contribution of feedforward, lateral and feedback connections to the classical receptive field center and extraclassical receptive field surround of primate V1 neurons. Prog Brain Res 154:93-120.

Baccus SA, Meister M (2002) Fast and slow contrast adaptation in retinal circuitry. Neuron 36:909-919.

Barlow HB, Derrington AM, Harris LR, Lennie P (1977) The effects of remote retinal stimulation on the responses of cat retinal ganglion cells. J Physiol 269:17794.

Beaudoin DL, Borghuis BG, Demb JB (2007) Cellular basis for contrast gain control over the receptive field center of mammalian retinal ganglion cells. J Neurosci 27:2636-2645.

Belgum JH, Dvorak DR, McReynolds JS (1982) Sustained synaptic input to ganglion cells of mudpuppy retina. J Physiol 326:91-108.

Breitmeyer B, Valberg A, Kurtenbach W, Neumeyer C (1980) The lateral effect of oscillation of peripheral luminance gratings on the foveal increment threshold. Vision Res 20:799-805.

Brown SP, Masland RH (2001) Spatial scale and cellular substrate of contrast adaptation by retinal ganglion cells. Nat Neurosci 4:44-51.

Chen EP, Linsenmeier RA (1989) Center components of cone-driven retinal ganglion cells: differential sensitivity to 2-amino-4-phosphonobutyric acis. J Physiol 419:77-93.

Cleland BG, Levick WR (1974) Properties of rarely encountered types of ganglion cells in the cat's retina and an overall classification. J Physiol 240:457-492.

Demb JB, Haarsma L, Freed MA, Sterling P (1999) Functional circuitry of the retinal ganglion cell's nonlinear receptive field. J Neurosci 19:9756-9767.

Demb JB, Zaghloul K, Haarsma L, Sterling P (2001) Bipolar cells contribute to nonlinear spatial summation in the brisk-transient $\mathrm{Y}$-ganglion cell in mammalian retina. J Neurosci 21:7447-7454.

Derrington AM, Lennie P, Wright MJ (1979) The mechanism of peripherally evoked responses in retinal ganglion cells. J Physiol 289:299-310.

Enroth-Cugell C, Jakiela HG (1980) Suppression of cat retinal ganglion cell responses by moving patterns. J Physiol 302:49-72.

Fitzpatrick D (2000) Seeing beyond the receptive field in primary visual cortex. Curr Opin Neurobiol 10:438-443.

Frishman LJ, Linsenmeier RA (1982) Effects of picrotoxin and strychnine on nonlinear responses of Y-type cat retinal ganglion cells. J Physiol 324:347-363

Frishman LJ, Freeman AW, Troy JB, Schweitzer-Tong DE, Enroth-Cugell C (1987) Spatiotemporal frequency responses of cat retinal ganglion cells. J Gen Physiol 89:599-628.

Greschner M, Bongard M, Rujan P, Ammermüller J (2002) Retinal ganglion cell synchronization by fixational eye movements improves feature estimation. Nat Neurosci 5:341-347.

He ZJ, Loop MS (1990) Peripheral field stimulation affects foveal flicker, but not sensitivity. Vision Res 30:1107-1110.

Hennig MH, Funke K, Wörgötter F (2002) The influence of different retinal subcircuits on the nonlinearity of ganglion cell behavior. J Neurosci 22:8726-8738.

Hochstein S, Shapley RM (1976) Linear and nonlinear spatial subunits in Y cat retinal ganglion cells. J Physiol 262:265-284.

Kim KJ, Rieke F (2003) Slow $\mathrm{Na}^{+}$inactivation and variance adaptation in salamander retinal ganglion cells. J Neurosci 23:1506-1516.

Kruger J, Fischer B (1973) Strong periphery effect in cat retinal ganglion cells. Excitatory responses in ON- and OFF-center neurons to single grid displacements. Exp Brain Res 18:316-318.

Levick WR, Oyster CW, Davis DL (1964) Evidence that McIlwain's periphery effect is not a stray light artifact. J Neurophysiol 28:555-57.
Marc RE, Murry RF, Fisher SK, Linberg KA, Lewis GP, Kalloniatis M (1998) Amino acid signatures in the normal cat retina. Invest Ophthalmol Vis Sci 39:1685-1693.

Margolis DJ, Detwiler PB (2007) Different mechanisms generate maintained activity in ON and OFF retinal ganglion cells. J Neurosci 27:5994-6005

McIlwain JT (1964) Receptive fields of optic tract axons and lateral geniculate cells: peripheral extent and barbituate sensitivity. J Neurophysiol 27:1154-1173.

Mitra P, Miller RF (2007) Normal and rebound impulse firing in retinal ganglion cells. Vis Neurosci 24:79-90.

Noda H, Adey WR (1974) Retinal ganglion cells of the cat transfer information on saccadic eye movement and quick target motion. Brain Res 70:340-345.

Nolt MJ, Kumbhani RD, Palmer LA (2004) Contrast-dependent spatial summation in the lateral geniculate nucleus and retina of the cat. J Neurophysiol 92:1708-1717.

Nolt MJ, Kumbhani RD, Palmer LA (2007) Suppression at high spatial frequencies in the lateral geniculate nucleus of the cat. J Neurophysiol 98:1167-1180.

Olveczky BP, Baccus SA, Meister M (2003) Segregation of object and background motion in the retina. Nature 423:401-408.

Passaglia CL, Enroth-Cugell C, Troy JB (2001) Effects of remote stimulation on the mean firing rate of cat retinal ganglion cells. J Neurosci 21:5794-5803.

Rapaport DH, Stone J (1988) The periphery effect in cat retinal ganglion cells: variation with functional class and eccentricity. Exp Brain Res 70:73-78.

Rodieck RW (1965) Quantitative analysis of cat retinal ganglion cell response to visual stimuli. Vision Res 5:583-601.

Roska B, Werblin F (2003) Rapid global shifts in natural scenes block spiking in specific ganglion cell types. Nat Neurosci 6:600-608.

Roska B, Nemeth E, Werblin FS (1998) Response to change is facilitated by a three-neuron disinhibitory pathway in the tiger salamander retina. J Neurosci 18:3451-3459.

Shapley RM, Victor JD (1978) The effect of contrast on the transfer properties of cat retinal ganglion cells. J Physiol 285:275-298.

Smirnakis SM, Berry MJ, Warland DK, Bialek W, Meister M (1997) Adaptation of retinal processing to image contrast and spatial scale. Nature 386:69-73.

Solomon SG, Lee BB, Sun H (2006) Suppressive surrounds and contrast gain in magnocellular-pathway retinal ganglion cells of macaque. J Neurosci 26:8715-8726.

Vaney DI (1994) Patterns of neuronal coupling in the retina. Prog Ret Eye Res 13:301-355.

Victor JD (1987) The dynamics of the cat retinal X cell center. J Physiol 386:219-246.

Victor JD (1988) The dynamics of the cat retinal Y cell subunit. J Physiol 405:289-320

Xin D, Bloomfield SA (1997) Tracer coupling pattern of amacrine and ganglion cells in the rabbit retina. J Comp Neurol 383:512-528.

Zaghloul KA, Boahen K, Demb JB (2003) Different circuits for ON and OFF retinal ganglion cells cause different contrast sensitivities. J Neurosci 23:2645-2654.

Zaghloul KA, Boahen K, Demb JB (2005) Contrast adaptation in subthreshold and spiking responses of mammalian Y-type retinal ganglion cells. J Neurosci 25:860-868.

Zaghloul KA, Manookin MB, Borghuis BG, Boahen K, Demb JB (2007) Functional circuitry for peripheral suppression in mammalian Y-type retinal ganglion cells. J Neurophysiol 97:4327-4340. 